\title{
Perbedaan Komunikasi Ilmiah Siswa Melalui Implementasi Kartu Kuarted
}

\author{
Isnaeni Nur Widiyanti, Mobinta Kusuma, Muriani Nur Hayati
}

(C) 2020 JEMS (Jurnal Edukasi Matematika dan Sains)

This is an open access article under the CC-BY-SA license (https://creativecommons.org/licenses/bysa/4.0/) ISSN 2337-9049 (print), ISSN 2502-4671 (online)

\begin{abstract}
Abstrak:
Penelitian ini bertujuan untuk mengetahui perbedaan komunikasi ilmiah melalui implementasi kartu kuartet dan respon siswa setelah menggunakan implemtasi kartu kuartet. Penelitian yang dilaksanakan menggunakan pendekatan kualitatif. Jenis penelitian ini adalah eksperimen dengan desain posttest only control grup. Lokasi penelitian ini adalah salah satu sekolah menengah pertama di kramat kabupaten tegal. Metode pengumpulan data menggunakan tes, kuesioner dan dokumentasi. Teknik analisis data yang digunakan uji purposiv sampling, uji intrumen yang meliputi uji validitas teoritis (validitas isi dan konstruk), uji validitas empiris (rasch model), uji prasyarat analisis (uji normalitas, uji homogenitas), anlaisis uji hipotesis (independen sample t-test) dan analisis kuesioner. Hasil penelitian ini menyatakan bahwa: hasil perbedaan komunikasi ilmiah siswa melalui implementasi kartu kuartet dengan menggunakan independen sample t-test memperoleh yang signifikan yaitu $0,00<0,05$, dan respon siswa setelah menggunakan kartu kuartet sangat tinggi.
\end{abstract}

Kata Kunci: Komunikasi Ilmiah, Siswa, Kartu Kuarted

\begin{abstract}
:
This study aims to determine the differences in scientific communication through the implementation of quartet cards and student responses after using the implementation of a quartet card. Research conducted using a qualitative approach. This type of research is an experiment with a posttest only control group design. The location of this study is one of the junior high schools in Kramat Tegal. Methods of data collection using tests, questionnaires and documentation. Data analysis techniques used were purposive sampling, instrument testing which included tests of theoretical validity (content and construct validity), empirical validity tests (rasch models), analysis prerequisite tests (normality tests, homogeneity tests), analysis of hypothesis tests (independent sample t- test) and questionnaire analysis. The results of this study state that: the results of differences in scientific communication of students through the implementation of a quartet card using an independent sample t-test obtained a significant of $0.00<0.05$, and the response of students after using a quartet card is very high.
\end{abstract}

Keywords: Scientific Communication, Students, Quarted Cards

\section{Pendahuluan}

Di abad ke-21, dunia mengalami perubahan yang sangat cepat. Perubahan ini menyangkut di segala kehidupan, yaitu bidang ekonomi, transportasi, teknologi, komunikasi, informasi, dan lain-lain. Perubahan ini perlu diantisipasi dengan menguasai keterampilan abad ke-21. Keterampilan abad ke-21 ini meliputi berpikir kritis dan pemecahan masalah, kreativitas dan inovasi, kolaborasi, dan komunikasi (Redhana, 2019).

Isnaeni Nur Widiyanti, Universitas Pancasakti Tegal isnaeni.nurwidiyanti@gmail.com

Mobinta Kusuma, Universitas Pancasakti Tegal mobintakusuma@upstegal.ac.id

Muriani Nur Hayati, Universitas Pancasakti Tegal murianinh@upstegal.ac.id 
Menurut Fenti dkk (2017) dalam penelitian yang dilakukan oleh Scot (2008), Komunikasi sangat penting untuk semua profesi karena hal yang pertama yang sering dilihat dari individu berdasarkan keterampilan komunikasinya dalam berkomunikasi secara lancar dan dimengerti, oleh karena itu keterampilan komunikasi peserta didik sangat penting untuk dievaluasi agar dapat mengetahui dengan jelas keterampilan komunikasi ilmiah yang dimiliki dan dikuasai oleh peserta didik.

Berdasarkan hasil wawancara yang dilakukan pada salah satu guru yang di sekolah tempat penelitian dapat disimpulkan bahwa kegiatan pembelajaran yang melibatkan proses komunikasi ilmiah jarang dilakukan, penggunaan media pembelajaran juga masih jarang dilakukan karena keterbatasan waktu. Hal ini karena guru cenderung fokus pada materi ujian nasional. Penelitian yang dilakukan oleh Sugiarti, dkk (2015) menyatakan bahwa beberapa siswa yang sudah memahami materi belum bisa mengkomunikasikan pengetahuan yang dimiliknya kepada orang lain, hal ini disebabkan karena komunikasi ilmiah siswa cenderung rendah. Proses belajar mengajar pada dasarnya juga merupakan proses komunikasi, sehingga media yang digunakan dalam pembelajaran disebut media pembelajaran (Falahudin, 2014). Proses pembelajaran yang kurang efektif dan menarik membuat peserta didik kurang aktif dalam kegiatan pembelajaran, sehingga peserta didik kurang memahami materi yang disampaikan oleh guru sehingga komunikasi ilmiah rendah dan pembelajaran tidak tercapai sepenuhnya.

Media kartu kuartet merupakan salah satu media pembelajaran yang membantu pembelajaran IPA yang mencangkup perubahan bentuk peningkatan pembelajaran. Siswa dapat menyelesaikan kartu kuartet dengan cara pengelompokan kartu yang sejenis dan dapat mengarahkan kekomunikasi ilmiahnya siswa (Fauziyah, 2017).

Media kartu kuartet memiliki kelebihan yaitu praktis, dan mudah di mainkan kapan saja. Kartu kuartet dapat membantu guru sebagai sarana prasarana dalam media pembelajaran mandiri dan dapat mencapai kompetensi yang sudah ditargetkan. Media kartu kuartet juga memiliki kelemahan yaitu siswa dapat mengalami distraksi sehingga tujuan pembelajaran kurang tercapai (siswa lebih fokus pada permainan kartu kuartet). Arsyad (2011) menyimpulkan bahwa media pembelajaran adalah komponen sumber belajar atau wahana fisik yang mengandung materi instruksional di lingkungan siswa yang dapat merangsang siswa untuk belajar.

Proses pembelajaran guru mempunyai tugas untuk mendorong, membimbing dan memberi fasilitas belajar bagi siswa untuk mencapai tujuan Melalui perannya sebagai seorang pengajar, guru diharapkan mampu mendorong siswa untuk senantiasa belajar dalam berbagai kesempatan melalui berbagai sumber dan media (Slameto, 2010). Pembelajaran IPA merupakan salah satu tipe pembelajaran yang dianjurkan dan diaplikasikan pada jenjang pendidikan dasar dan pendidikan menengah pertama (Taufiq, dkk. 2014). Ilmu Pengetahuan Alam (IPA) adalah salah satu mata pelajaran yang berkaitan dengan mengetahui alam secara sistematis.

Ilmu Pengetahuan Alam (IPA) adalah salah satu mata pelajaran yang berkaitan dengan mengetahui alam secara sistematis. IPA bukan hanya kumpulan pengetahuan yang berupa fakta, konsep, atau prinsip saja, tetapi juga merupakan suatu proses penemuan. Pendidikan IPA di Sekolah Menengah Pertama (SMP) diharapkan menjadi wahana bagi siswa untuk mempelajari dirinya sendiri dan alam sekitarnya (Nurdyansyah, 2018). IPA merupakan salah satu mata pelajaran penting yang diajarkan di sekolah. Namun kenyataannya, IPA sering dianggap sebagai mata pelajaran yang sulit oleh siswa karena hanya berupa hafalan fakta-fakta. Pembelajaran IPA di sekolah masih difokuskan pada penguasaan konsep. Strategi 
pembelajaran berpikir tidak digunakan secara baik dalam setiap proses pembelajaran. Hal ini menyebabkan siswa menjadi kurang dapat mengembangkan keterampilan proses dalam memperoleh produk IPA. Terkait dengan kondisi tersebut maka hakikat IPA yang meliputi produk dan proses belum terlaksana (Umar, 2016).

Yaumi (2017) menyampaikan bahwa, implementasi pembelajaran IPA untuk SMP/MTs sendiri sejak kurikulum 2006 berdasarkan ketentuan Kementerian Pendidikan Nasional merupakan pembelajaran yang bersifat integrated atau terpadu. Pemanasan global merupakan salah satu contoh materi IPA yang dipelajari pada jenjang SMP/MTs kelas VII. Pemahaman akan konsep dasar materi pemanasan global perlu ditekankan pada siswa sejak dini, agar mereka mengerti apa yang dimaksud pemanasan global, apa penyebab pemanasan global, apa dampak pemanasan global dan apa upaya penanggulangan pemanasan global, sehingga dapat menentukan cara-cara penanggulangan yang tepat untuk menangani pemanasan global ini.

Berdasarkan uraian masalah yang dijelaskan diatas peneliti melakukan suatu penelitian yang berjudul "Perbedaan Komunikasi Ilmiah melalui Implementasi Media Kartu Kuartet pada Materi Pemanasan Global".

\section{Metode}

Penelitian ini dilaksanakan pada siswa kelas VII semester II Tahun Pelajaran 2019/2020 di salah satu Sekolah Menegah Pertama di Kramat Kabupaten Tegal dengan jenis penelitian eksperimen semu (quasi experimental) dimana penelitian yang dilakukan dengan cara memberikan perlakuan atau treadment tertetu (Sugiyono, 2015). antara kelas eksperimen yang diberikan perlakuan, kelas eksperimen yang diaja dengan menggunakan Kartu kuartet sedangkan kelas kontrol yang diajar tanpa menggunakan kartu kuartet.

Penelitian ini merupakan penelitian eksperimen. Metode penelitian eksperimen dapat diartikan sebagai metode penelitian yang digunakan untuk mencari perbedaan atau pengaruh perlakuan tertentu terhadap yang lain dalam kondisi yang terkendalikan (Sugiyono, 2010:107). Perlakuan dalam penelitian ini perbedaan komunikasi ilmiah siswa terhadap penerapan kartu kuartet.

Penelitian ini yaitu pendekatan kuantitatif. Pengambilan data telah dilaksanakan pada tanggal 1 oktober 2019 sampai 6 januari 2020 yaitu semester II tahun pelajaran 2016/2017 yang bertempat di salah satu Sekolah Menengah Pertama di Kramat Kabupaten Tegal. Populasi dari penelitian ini adalah seluruh siswa kelas VII Sekolah Menengah Pertama di Kramat Kabupaten Tegal yang berjumlah 120 siswa terdiri atas 3 kelas (kelas VII A sampai kelas VII C). Sampel dalam penelitian ini ditetapkan adalah kelas VII A sebagai kelas eksperimen berjumlah 34 siswa, kelas VII B berjumlah 34 siswa sebagai kelas kontrol sedangkan kelas VII C sebagai kelas uji coba.Pengambilan sampel dalam penelitian ini menggunakan purposive sampling dengan menggunakan pertimbangan terentu.

Desain penelitian merupakan rancangan bagaimana proses penelitian tersebut dilaksanakan. Pada penelitian ini akan mengetahui perbedaan komunikasi ilmiah melalui implemantasi kartu kuartet. Adapun desain penelitian ini dapat dilihat pada Tabel 1.

Tabel 1. Desain Penelitian

\begin{tabular}{ccc}
\hline Kelas & Perlakuan & Posttest \\
\hline Eksperimen & $\mathrm{Y}_{1}$ & $\mathrm{Z}_{1}$ \\
\hline Kontrol & $\mathrm{Y}_{2}$ & $\mathrm{Z}_{2}$ \\
\hline
\end{tabular}

Keterangan : 
Z1 : Hasil tes siswa kelas eksperimen setelah diberi perlakuan

Z2 : Hasil tes siswa kelas kontrol setelah di berikan perlakuan

Y1 : Perlakuan di kelas eksperimen menggunakan media kartu kuartet

Y2 : Perlakuan di kelas kontrol tanpa menggunakan media kartu kuartet

Teknik pengumpulan data yang digunakan dalam penelitian meliputi 3 teknik yaitu teknik dokumentasi, teknik tes dan kuesioner. Instrumen yang digunakan dalam penelitian ini adalah tes komunikasi ilmiah dan respon kuesioner. Teknik analisis data menggunakan : (1) Uji validitas teoritis yang meliputi validitas isi dan validitas konstruk, (2) Uji validitas empiris yang menggunakan rasch model. Teknik Analisis Data yang digunakan yaitu uji intrumen, uji prasyrat, uji hipotesis dan uji kuesioner. Uji instrumen meliputi uji validitas teoritis (validitas isi dan validitas konstruk) dan uji validitas empiris (rasch model) (Susongko 2019). Uji prasyrat meliputi uji normalitas kolmogorov-smirnov, uji homogenitas (Susongko, 2015). Uji Hipotesis digunakan untuk mengetahui perbedaan komunikasi ilmiah melalui implementasi kartu kuartet pada kedua kelas, kelas eksperimen dan kelas kontrol. Uji kuesioner digunakan untuk mengetahui respon siswa setelah menggunakan media kartu kuartet.

\section{Hasil dan Pembahasan}

Berdasarkan hasil perhitungan prasyarat analisis yang meliputi uji normalitas dapat dilihat dari nilai sig anatara kelas eksperimen dan kelas kontrol lebih besar dari 0,05 yakni kelas eksperimen 0,075 > 0,05 sedangkan kelas kontrol 0,200 > 0,05. Sehingga dapat disimpulkan bahwa data keduanya berdistribusi normal.

Berdasarkan hasil perhitungan prasyarat kedua uji homogenitas setelah uji normalias. Bertujuan untuk melihat kesamaan dua kelas penelitian antara kelas eksperimen dan kelas kontrol. Kedua kelas penelitian dikatakan homogen apabila hasil antara kelas keksperimen dan kelas kontrol lebih besar dari 0,005 atau a $>0,05$. Dapat dilihat hasil sig perhitungan homogenitas dengan menggunakan software SPSS 17.0 lebih besar dari 0,05 yakni 0,136 >0,05.

Berdasarkan hasil perhitungan menggunakan analisis uji independent sampel t-test zhitung=10,924. Selanjutnya hasil tersebut dikonsultasikan dengan nilai ztabel dengan kriteia pengujian 5\% didapatkan ztabel=1,674. Karena zhitung>ztabel maka Ho ditolak, jadi komunikasi ilmiah siswa melalui implementasi kartu kuartet mencapai target.

Tabel 2. Hasil Posttest Komunikasi Ilmiah Kelas Eksperimen

\begin{tabular}{ccc}
\hline & Posttest & Valid N (listwise) \\
\hline Minimum & 55 & 34 \\
Maksimum & 95 & \\
\hline Rata-rata & 75 & \\
\hline
\end{tabular}

Tabel 3. Hasil Posttest Komunikasi Ilmiah Kelas Kontrol

\begin{tabular}{ccc}
\hline & Posttest & Valid N (listwise) \\
\hline Minimum & 25 & 34 \\
\hline Maksimum & 80 & \\
\hline Rata-rata & 52 & \\
\hline
\end{tabular}

Hasil posttest komunikasi kelas eksperimen dan kelas kontrol Tabel 2 dan Tabel 3, menujukan bahwa ada perbedaan komunikiasi ilmiah pada kelas eksperimen dan kelas kontrol. 
Kelas eksperimen proses pembelajaran menggunakan kartu kuartet yang diperoleh nilai ratarata 75, sedangkan kelas kontrol proses pembelajarannya tanpa menggunakan kartu kuartet dengan hasil rata-rata 55. Dari hasil tersebut dapat diketahui bahwa penerapan media kartu kuartet pada kelas eksperimen berpengaruh hasil nilai posttest komunikasi ilmiah. Hal ini juga dapat dilihat dari hasil persentase indikator yaitu membaca grafik, membaca tabel dan berfikir kreatif. Dari hasil perhitungan setiap indikator pada kelas eksperimen mendapatkan nilai 26\% siswa menyelesaikan soal posttest berbentuk grafik, 27,5\% siswa menyelesaikan soal posttes berbentuk tabel, dan 27,5\% siswa dapat menyelesaikan soal posttes dengan berfikir kreatif. Sedangkan pada kelas kontrol mendapatkan nilai 13\% siswa menyelesaikan soal posttest berbentuk grafik, 18\% siswa menyelesaikan soal posttes berbentuk tabel, dan 17,6\% siswa dapat menyelesaikan soal posttes dengan berfikir kreatif.

Tabel 4. Hasil Presentase Tiap Indikator

\begin{tabular}{ccc}
\hline Indikator keterampilan komunikasi ilmiah & Kelas eksperimen & Kelas kontrol \\
\hline Membaca grafik & $26 \%$ & $13 \%$ \\
\hline Membaca tabel & $27,5 \%$ & $18 \%$ \\
\hline Berfikir kreatif & $27,2 \%$ & $17,6 \%$ \\
\hline
\end{tabular}

Selanjutnya hasil respon siswa setelah menggunakan kartu kuartet dengan hasil persentse yang diperoleh adalah 80,15\% yang artinya respon siswa terhadap media kartu kuartet sanggat tinggi. Hal ini dibuktikan bahwa permainan kartu kuartet tertarik untuk digunakan sebagai media pembelajaran IPA. Menurut Hamid (2018) mengatakan bahwa pembelajaram yang menyenangkan biasanya dilakukan deangan cara humor, bermain peran, dan demostrasi.

Tabel 5. Hasil Kuesioner Siswa

\begin{tabular}{cc}
\hline Ukuran & Nilai Kelas Eksperimen \\
\hline Mean & 48,1 \\
Median & 45 \\
Maximum & 54 \\
Minimum & 45 \\
Std. Deviasi & 3,5 \\
Persentase & 80,15 \\
\hline
\end{tabular}

Tabel 5 menunjukan hasil kuesioner siswa, respon nilai rata-rata sebesar 48,1, nilai median sebesar 45, nilai maximum sebesar 54, nilai minimum sebesar 45 dan Std. Deviasi sebesar 3,5. Hasil ini menunjukan kartu kuartert dapat mempengaruhi dan membuat semangat dalam mengikuti proses pembelajaran. Hal ini didukung dengan penelitian yang dilakukan oleh (Fauziah:2017) bahwa, media kaertu kuartet dapat membangkitkan respon motivasi untuk terlibat secara aktif dalam pembelajaran, membantu memahami materi, melatih keterampilan berkomunikasi, aktif bertanya dan menjawab pertanyaan.

Sadirman (2010) mengatakan bahwa media permainan bersifat luwes, permainan dapat dipakai berbagai tujuan pendidikan salah satunya adalah untuk ketrampilan komunikasi ilmiah. Selain itu ada empat alasan penting pembelajaran menggunakan media menurut Rasyid (2017) diantaranya, media kartu kuartet dapat membangkitkan belajar siswa secara individu, siswadapat mengembangkan ketrampilan dasar dalam mengkomunikasikan kartu kuartet, 
dapat dijadikan wahana belajar pendekatan ilmiah dan yang terakhir kartu kuartet dapat menunjang pemahaman materi IPA.

\section{Simpulan}

Berdasarkan hasil analisis dalam pembahasan pada siswa kelas VII salah satu sekolah menengah pertama yang ada di kramat kabupaten tegal tahun ajaran 2018/2019, bahwa Perbedaan komunikasi ilmiah siswa dapat diketahui dari hasil nilai rata-rata posttest antara kelas eksperimen sebesar 75 dan kelas kontrol sebesar 55, dan hasil respon presentase siswa setelah menggunakan kartu kuartet sangat tinggi yaitu 80,15\%. Hal ini membuktikkan bahwa kartu kuartet merupakan media permainan yang memiliki keluwesan untuk mencapai tujuan pendidikan salah satunya yaitu komunikasi ilmiah pada materi pemanasan global.

Disarankan untuk peneliti selanjutnya agar peneliti selanjutnya benar-benar memahami bagaimana metode pembelajaran IPA dengan menggunakan media untuk meningkatkan komunikasi ilmiah siswa agar penelitian dapat dilaksanakan secara maksimal dan memperoleh hasil yang maksimal juga.

\section{Daftar Rujukan}

Arsyad, Azhar. 2011. “Media Pembelajaran”. Jakarta : PT Raja Grafindo Persada.

Falahudin, I. 2014. "Pemanfaatan media dalam pembelajaran". Jurnal Lingkar Widyaiswara, $1(4), 104-117$.

Fauziyah,T.A. 2017. "Pengembangan Media Permainan Sains Quartet untuk Meningkatkan Hasil Belajar Dan Ketrampilan Berkomunikasi". Pendidikan Sains, 5(02).

Fenti, S., Patonah, S., \& Nuroso, H. 2017. “Pengembangan Instrumen Keterampilan Komunikasi Ilmiah dalam Pembelajaran Fisika". Jurnal Penelitian Pembelajaran Fisika, 8(2).

Nurdyansyah, N. 2018. Model Pembelajaran Berbasis Masalah Pada Pelajaran IPA Materi Komponen Ekosistem". Universitas Muhammadiyah Sidoarjo.

Redhana, I. W. 2019. “Mengembangkan Keterampilan Abad Ke-21 Dalam Pembelajaran Kimia”. Jurnal Inovasi Pendidikan Kimia, 13(1).

Scot S.2008. "Perception of Students Learning Critical Thinking through Debate in a Technology" Classroom: A Case Study The Journal of Technology Studies.

Slameto. 2010. “Belajar dan Faktor-faktor yang Mempengaruhinya”. Jakarta: Rineka Cipta.

Sugiarti, I. 2012. "Pengaruh Metode Pembelajaran Problem Solving terhadap Kemampuan Komunikasi Matematika Siswa Kelas VIII Mts Ma'arif NU 7 Sawojajar brebes pada Sub Pokok Bahasan Bangun Ruang Sisi Datar “.(Doctoral dissertation, IAIN Syekh Nurjati Cirebon). 
Sugiyono. 2015. “Metode penelitian pendidikan (pendekatan kuantitatif, kualitatif dan R\&D)”. Bandung: Alfabeta.

Taufiq, M., Dewi, N. R., \& Widiyatmoko, A. 2014. “Pengembangan media pembelajaran IPA terpadu berkarakter peduli lingkungan tema "konservasi" berpendekatan scienceedutainment". Jurnal Pendidikan IPA Indonesia, 3(2).

Umar, N. H. M., Parmin, P., \& Wusqo, I. U. 2016. “Pengaruh Media Kartu Pintar Tumbuhan Berbasis Science Edutainment Terhadap Minat Belajar dan Pemahaman Konsep Siswa Tema Gerak Tumbuhan". Unnes Science Education Journal, 5(2).

Yaumi, Y. 2017. "Penerapan Perangkat Model Discovery Learning pada Materi Pemanasan Global untuk Melatihkan Kemampuan Literasi Sains Siswa SMP Kelas VII". Pensa: Jurnal Pendidikan Sains, 5(1). 